Research Article

\title{
Study on Fuzzy Control for Air-To-Water Heat Pumps Connected to a Residential Floor Heating System
}

\author{
Duhui Jiang (iD) and Cui Hongshe $(1)$ \\ School of Environment and Municipal Engineering, Qingdao University of Technology, Qingdao 266033, China \\ Correspondence should be addressed to Cui Hongshe; cuihongshe@sina.com
}

Received 18 September 2019; Accepted 11 November 2019; Published 5 March 2020

Academic Editor: Yannis Dimakopoulos

Copyright (c) 2020 Duhui Jiang and Cui Hongshe. This is an open access article distributed under the Creative Commons Attribution License, which permits unrestricted use, distribution, and reproduction in any medium, provided the original work is properly cited.

\begin{abstract}
Reducing the supplied water temperature of the air-to-water heat pump to meet the building heat demand can greatly improve the efficiency of the heat pump unit and give full play to the advantages of energy saving and comfort of the floor radiant heating system with an air-to-water heat pump. Based on the variation of ambient temperature and ambient temperature, the domain of fuzzy control is optimized by particle swarm optimization (PSO), and the optimal fuzzy control table is established to adjust the supplied water temperature of the air-to-water heat pump. A transient simulation model of floor radiant heating system for a typical $100 \mathrm{~m}^{2}$ building in China cold regions was developed by using TRNSYS software, and this heating system is simulated by the fuzzy control variable supplied water temperature and the conventional $45^{\circ} \mathrm{C}$ supplied water control in the whole heating season. The simulation results show that the system energy consumption is saved by $15.9 \%$ and SCOP increased by $18.9 \%$ by using this fuzzy control compared with the conventional $45^{\circ} \mathrm{C}$ supplied water control in the whole heating season under the premise of ensuring stable room temperature. Comparing conventional $45^{\circ} \mathrm{C}$ supplied water control, the fuzzy control can reduce $\mathrm{CO}_{2}$ emissions by $4.3 \mathrm{~kg} / \mathrm{m}^{2}, 4.7 \mathrm{~kg} / \mathrm{m}^{2}, 5.6 \mathrm{~kg} / \mathrm{m}^{2}, 5.2 \mathrm{~kg} / \mathrm{m}^{2}$, and $4.9 \mathrm{~kg} / \mathrm{m}^{2}$ in Zhengzhou, Qingdao, Beijing, Taiyuan, and Zhangjiakou, respectively.
\end{abstract}

\section{Introduction}

Recently, the radiant heating system has been widely applied in residential buildings. Radiant floor heating systems are installed in $85 \%$ of rural houses in northern China and almost all residential buildings in Korea $[1,2]$. Floor heating can accept lower temperature hot water. The combination of air-to-water heat pump and floor radiant heating can give full play to the advantages of air-to-water heat pump low temperature and high efficiency and floor radiant heating comfort and energy saving.

The supplied water temperature of the air-to-water heat pump has a great influence on the efficiency of the heat pump unit. Under the premise of ensuring the stability of the room temperature, reasonable optimization of the supplied water temperature is the key to the control of the heating system. Leiqh et al. analyze and study the relationship between the supplied water temperature of the floor radiant heating system and the outdoor temperature and conclude that there is a linear relationship between the outdoor temperature and the required supplied water temperature [3]. Olesen et al's. dynamic simulations show that the water temperature in the pipe (the supplied water temperature or the average temperature of the supplied and return water) is controlled by the outdoor temperature, which has better energy conservation and economy [4]. The latest advances in computing software and communications equipment have enabled us to develop optimized control strategies to address the challenges of intrinsic heating system control strategies [5]. Karlsson et al. optimize the supplied fluid temperature by predicting the room heat demand. The control method is applicable to a single room, the supplied fluid temperature is stable, and the predicted heat demand is good [6]. Liu et al. establish the airto-water heat pump floor radiant heating system simulation model through EnergyPlus and BCVTB and propose a variable supplied water temperature control for the $100 \mathrm{~m}^{2}$ actual 
residential area in Shanghai. The heating season is energysaving under the control by $40 \%$ [7].

Heating efficiency of the air-to-water heat pump is obviously affected by the outdoor temperature, and the outdoor temperature also has an obvious effect on the building heat load. Therefore, there is a basis for controlling the supplied water temperature according to the outdoor temperature. However, due to the thermal inertia of the building envelope, to maintain the stability of the room temperature, the air-to-water heat pump floor radiant heating system needs to supplement the heat lost by the building in time. A building energy model (BEM) is very important for predicting the energy consumption of the heating system. BEM can be broadly classified into a white box model (EnergyPlus [8], TRNSYS [9], etc.), a black box model (artificial neural network (ANN) [10, 11], support vector machine (SVM) [12], fuzzy logic (FL) [13], etc.), and a gray box model (between white and black boxes [14-16]). They use real data and physical equations to determine behavioral buildings [17]. The BEM in TRNSYS is a good model for predicting the state of the building because they allow the definition of all the elements that affect its energy behavior. The accuracy of the TRNSYS software has been validated [18-20].

For multiroom buildings, the paper uses MATLAB software to develop a fuzzy control table, taking the ambient temperature during the heating season, the difference between the current ambient temperature and the ambient temperature at the previous hour as the variables, and formulate the fuzzy control table of the variable-supplied water temperature of the air-to-water heat pump. Under the premise of ensuring the heat demand of the building, the heat pump unit operates at the lowest supplied water temperature, which is the key to energy saving. The existing literature mostly uses energy consumption, cost savings, predicted mean vote (PMV), or predicted percentage dissatisfied (PPD) as the optimization target [21-24]. The objective function considers the energy consumption of the heating system and the room temperature to be stable by using the particle swarm optimization (PSO) algorithm to optimize the fuzzy control table on the GenOpt [25] software. There are many commonly used heuristic algorithms including PSO [26], genetic algorithm (GA) [27, 28], firefly algorithm [29], memetic algorithm [30], evolutionary algorithm (EA) [31], and artificial bee colony (ABC) optimization algorithm [32]. PSO algorithm was first proposed by Professor Kennedy in the United States [33]. Through the cooperation and competition among individuals, the optimal solution search in complex space is realized.

The organization of this paper is as follows. Section 2 builds the model on TRNSYS and explains the proposed methodology. And then, Section 3 takes the typical buildings in rural areas of Beijing as an example. Section 4 discusses energy-saving effect of variable-supplied water temperature control in Zhengzhou, Qingdao, Beijing, Taiyuan, and Zhangjiakou. Lastly, Section 5 summarizes the conclusions.

\section{Models and Methods}

This paper builds a model of air-to-water heat pump floor radiant heating system through TRNSYS. The building model and the floor radiant coil model use the type56 module in TRNSYS. Buried pipe model comes from RCmodels [34]. The climate database TMY2 (typical weather year) includes 10 years of meteorological data and provides statistical climatic conditions for TRNSYS simulation [35].

Verhelst et al. [36] discussed the advantages and disadvantages of different degrees of simplification of the heat pump model and applicable conditions. Based on the TRNSYS air-to-water heat pump model, this paper uses the empirical formula in the literature to defrosting the heat pump unit COP [37]. The performance parameters of the heat pump unit and the unit test data are provided by McQuay.

$$
\begin{aligned}
\mathrm{CAP}_{r}= & -0.0001836 \times t_{o} \times t_{o}-0.0000686 \times t_{g} \times t_{g} \\
& -0.0000815 \times t_{o} \times t_{g}+0.0190017 \times t_{o} \\
& +0.0021383 \times t_{g}+0.9515673 H_{1}(R 2=0.9972), \\
\mathrm{COP}_{r}= & -0.0000456 \times t_{o} \times t_{o}+0.0001571 \times t_{g} \times t_{g} \\
& -0.0003565 \times t_{o} \times t_{g}+0.0279493 \times t_{o} \\
& -0.0338114 \times t_{g}+2.1128644 H_{1}(R 2=0.9933),
\end{aligned}
$$

where $\mathrm{CAP}_{r}$ is the ratio of the performance curve heating capacity to the nominal operating condition, $\mathrm{COP}_{r}$ is the ratio of the performance curve COP to the nominal operating condition COP, $t_{o}$ is the outdoor temperature, and $t_{g}$ is the heat pump unit outlet temperature.

When the ambient temperature is lower than $7^{\circ} \mathrm{C}$ and higher than $7^{\circ} \mathrm{C}$, the $\mathrm{COP}$ attenuation value $\mathrm{COP}_{\mathrm{df}}$ caused by unit defrosting, as shown in the following equations:

$$
\begin{aligned}
& \operatorname{COP}_{\mathrm{df}}=-0.0027(t o-7)+0.1801 \exp \left(\frac{-t_{o}^{2}}{5}\right) \\
& \mathrm{COP}_{\mathrm{df}}=0.1801 \exp \left(\frac{-t_{o}^{2}}{5}\right) .
\end{aligned}
$$

The actual power consumption of the air-to-water heat pump is calculated as follows:

$$
\begin{aligned}
P_{m} & =\frac{\mathrm{CAP}_{c} \times \mathrm{CAP}_{r}}{\mathrm{COP}_{c} \times \mathrm{COP}_{r}\left(1-\mathrm{COP}_{\mathrm{df}}\right)}, \\
Q_{x} & =m \times C_{p}\left(t_{g}-t_{i}\right), \\
P_{\mathrm{lr}} & =\frac{Q_{x}}{\mathrm{CAP}_{c} \times \mathrm{CAP}_{r}}, \\
P_{\mathrm{awhp}} & =P_{m} \times F_{\text {flp }},
\end{aligned}
$$


where $P_{m}$ is full load power consumption, $P_{\text {awhp }}$ is air-towater heat pump actual power consumption, $Q_{x}$ is actual heating capacity, $P_{\operatorname{lr}}$ is partial load rate, $m$ is flow, and $t_{i}$ is the heat pump unit inlet temperature.

The actual power consumption of the water pump is calculated as follows:

$$
\begin{gathered}
P_{\text {pump }}=\frac{\rho g V H}{3600000 \eta} \\
\eta=\eta_{p} \eta_{m}, \\
P_{s}=P_{\text {pump }} \eta_{m},
\end{gathered}
$$

where $P_{\text {pump }}$ is pump power, $H$ is pump head, $V$ is flow of water flowing through the pump, $\eta$ is total pump efficiency, $\eta_{p}$ is pump motor efficiency, $\eta_{m}$ is pump shaft efficiency, and $P_{s}$ is pump shaft power.

The heat dissipation of the pipe is calculated as follows:

$$
\begin{aligned}
\mathrm{UA} & =\frac{1}{R_{\text {inside }}+R_{\text {pipe }}+R_{\text {insul }}+R_{\text {outside }}}, \\
R_{\text {inside }} & =\frac{1}{h_{\text {inside }}\left(\pi d_{\text {pipe }} L_{\text {pipe }}\right)}, \\
R_{\text {pipe }} & =\frac{\ln \left(\left(d_{\text {pipe }, o}\right) /\left(d_{\text {pipe }, i}\right)\right)}{2 \pi k_{\text {pipe }} L_{\text {pipe }}}, \\
R_{\text {insul }} & =\frac{\ln \left(\left(d_{\text {inside }, o}\right) /\left(d_{\text {pipe }, o}\right)\right)}{2 \pi k_{\text {insul }} L_{\text {pipe }}}, \\
R_{\text {outside }} & =\frac{1}{h_{\text {outside }}\left(\pi d_{\text {pipe }} L_{\text {pipe }}\right)}, \\
Q_{\text {env }, j} & =(\mathrm{UA})_{j}\left(t_{j}-t o\right)
\end{aligned}
$$

where UA is total heat transfer coefficient of pipeline, $R_{\text {inside }}$ is thermal resistance inside the pipe, $R_{\text {pipe }}$ is thermal resistance of the pipe, $R_{\text {insul }}$ is thermal resistance of thermal insulation, $R_{\text {outside }}$ is thermal resistance outside the pipe, $k_{\text {pipe }}$ is thermal conductivity of the pipe, $k_{\text {insul }}$ is thermal conductivity of the insulation, $h_{\text {inside }}$ is heat transfer coefficient inside the pipe, $h_{\text {outside }}$ is heat transfer coefficient outside the pipe, $d_{\text {pipe }}$ is pipe diameter, $L_{\text {pipe }}$ is pipe length, $Q_{\text {env }}$ is heat dissipation of the pipe, and $j$ is the various parts of the pipe fluid.

The valve is divided into a diverting valve and a mixing valve, and the energy flow models are, respectively, shown as follows:

$$
\begin{aligned}
m_{\mathrm{in}} C_{p}\left(t_{\mathrm{in}}-t_{\mathrm{div}}\right)= & m_{\mathrm{out}, 1}\left(t_{\mathrm{out}, 1}-t_{\mathrm{div}}\right)+m_{\mathrm{out}, 2}\left(t_{\mathrm{out}, 2}-t_{\mathrm{div}}\right) \\
& +m_{\mathrm{out}, 3}\left(t_{\mathrm{out}, 3}-t_{\mathrm{div}}\right)+m_{\mathrm{out}, 4}\left(t_{\mathrm{out}, 4}-t_{\mathrm{div}}\right) \\
& +m_{\mathrm{out}, 5}\left(t_{\mathrm{out}, 5}-t_{\mathrm{div}}\right), \\
m_{\mathrm{out}} C p\left(t_{\mathrm{out}}-t_{\mathrm{mix}}\right)= & m_{\mathrm{in}, 1}\left(t_{\mathrm{in}, 1}-t_{\mathrm{mix}}\right)+m_{\mathrm{in}, 2}\left(t_{\mathrm{in}, 2}-t_{\mathrm{mix}}\right) \\
& +m_{\mathrm{in}, 3}\left(t_{\mathrm{in}, 3}-t_{\mathrm{mix}}\right)+m_{\mathrm{in}, 4}\left(t_{\mathrm{in}, 4}-t_{\mathrm{mix}}\right) \\
& +m_{\mathrm{in}, 5}\left(t_{\mathrm{in}, 5}-t_{\mathrm{mix}}\right), \\
t_{\mathrm{in}}= & t_{\mathrm{div},}, \\
t_{\mathrm{out}}= & t_{\mathrm{mix}}, \\
t_{\mathrm{in}}= & \frac{\sum_{i=1}^{5} m_{\mathrm{out}, i} t_{\mathrm{out}, i}}{\sum_{i=1}^{5} m_{\mathrm{out}, i}} \\
t_{\mathrm{out}}= & \frac{\sum_{i=1}^{5} m_{\mathrm{in}, i} t_{\mathrm{in}, i}}{\sum_{i=1}^{5} m_{\mathrm{in}, i}}
\end{aligned}
$$

A two-position controller is used to control the room temperature between $18^{\circ} \mathrm{C}$ and $19^{\circ} \mathrm{C}$. On the premise of ensuring the stability of the room temperature, the heat lost by the building is replenished in time. The temperature of the outdoor environment is detected by the temperature sensor, and the current ambient temperature, the difference between the current ambient temperature, and the ambient temperature of the previous hour are used as variables, and the fuzzy control table is developed by using MATLAB. Output fuzzy control calculation results from MATLAB software to the TRNSYS.

The method of fuzzy control defuzzification uses the centroid method, and its expression formula is as shown in equation (8). The membership function in fuzzy control is trapmf type, and its expression formula is as shown in equation (9).

$$
\begin{gathered}
x_{n}=\frac{\sum_{i=1}^{n} x_{i} \mu\left(x_{i}\right)}{\sum_{i=1}^{n} \mu\left(x_{i}\right)}, \\
A(z)= \begin{cases}0, & z<c, \\
\frac{z-c}{d-c}, & c \leq z<d, \\
1, & d \leq z<e, \\
\frac{f-z}{f-e}, & e \leq z<f, \\
0, & f \leq z,\end{cases}
\end{gathered}
$$


where $x_{n}$ is the final value of the fuzzy control output; $x_{i}$ is the elements in the domain $(i=1,2,3,4,5, \ldots, n) ; \mu\left(x_{i}\right)$ is the fuzzy membership function; $c, d, e, f$, and $z$ are constant values, where $c<d<e<f ; A(z)$ is membership function output value.

We build five fuzzy subsets as $\{\mathrm{NB}, \mathrm{NS}, \mathrm{ZO}, \mathrm{PS}, \mathrm{PB}\}$. The fuzzy control decision table is shown in Table 1.

The setting supplied water temperature $t_{\text {set }}$ is between $25^{\circ} \mathrm{C}$ and $45^{\circ} \mathrm{C}$. The fuzzy control output table is shown in Table 2.

In order to improve the control precision, the domain of fuzzy control is optimized, that is, $a$ and $b$ are optimized under the condition that the control rule base is unchanged. The two parameters are coupled to each other. It is difficult to get the optimal value quickly and accurately by the conventional method. Therefore, the particle swarm optimization (PSO) algorithm on GenOpt software is used to optimize the parameters. As shown in Figure1, TRNSYS inputs the current room temperature $t_{o}(\mathrm{o})$, the previous hour room temperature $t_{o}(\mathrm{o}-\mathrm{h})$, and optimization value $a$ and $b$ to MATLAB.

Let the particle swarm search in an n-dimensional space. The basic formula of the particle swarm algorithm is as shown in the following equations:

$$
\begin{aligned}
V_{i b}(k+1)= & w V_{i b}(k)+c_{1} N_{1}\left(P_{i b \text { best }}(k)-Y_{i b}(k)\right) \\
& +c_{2} N_{2}\left(P_{\text {gbbest }}(k)-Y_{i b}(k)\right), \\
Y_{i b}(k+1)= & Y_{i b}(k)+V_{i b}(k+1),
\end{aligned}
$$

where $Y_{i b}(k)$ is the position of the particle $i$ in the $b_{\text {th }}$ dimension in the $k_{\text {th }}$ iteration; $V_{i b}(k)$ is the velocity of the particle $i$ in the $b_{\text {th }}$ dimension in the $k_{\text {th }}$ iteration; $P_{\text {ibbest }}(k)$ is the particle $i$ individual optimal position; $P_{g b \text { best }}(k)$ is the global optimal position of the whole particle swarm; $c_{1}$ and $c_{2}$ are learning factors; $w$ and $k$ are inertia factors and iteration times; and $N_{1}$ and $N_{2}$ are random numbers between $0-1$.

The vonNeumann topology is used, the maximum number of iterations is 500 , the cognitive acceleration is 2.8 , the social acceleration is 1.3 , the max velocity gain continuous is 0.5 , the maximum velocity discrete is 4 , the initial iteration is 1.2 , the final iteration is 0.5 , the number of particles is 20 , and the number of generations is 5 .

The objective function $M$ considers the energy consumption of the heating system and the room temperature to be stable. The stability of room temperature is expressed by unsatisfied time. Unsatisfied time is the time when the room temperature exceeds the setting temperature range of the room. The smaller the unsatisfied time is, the more stable the room temperature is. The objective function is as shown in the following equation:

$$
\begin{aligned}
M= & \frac{\sum_{0}^{H}\left(P_{\text {pump }}+P_{\text {awhp }}\right)}{\sum_{0}^{H}\left(P_{\text {pump }, 45}+P_{\text {awhp }, 45}\right)} \\
& +\frac{\sum_{0}^{H}\left(h_{\text {west }}+h_{\text {liv }}+h_{\text {bed }}+h_{\text {din }}\right)}{\sum_{0}^{H}\left(h_{\text {west }, 25}+h_{\text {liv }, 25}+h_{\text {bed }, 25}+h_{\text {din }, 25}\right)},
\end{aligned}
$$

TABLE 1: Fuzzy control decision table.

\begin{tabular}{ccccccc}
\hline & & \multicolumn{4}{c}{$t_{o}(\mathrm{o})-t_{o}(\mathrm{o}-\mathrm{h})$} \\
& & $\mathrm{NB}$ & $\mathrm{NS}$ & ZO & PS & PB \\
\hline \multirow{4}{*}{$t_{o}(\mathrm{o})$} & NB & PB & PB & PB & PMB & PM \\
& NS & PM & PMS & PS & ZO & NS \\
& ZO & PS & ZO & NS & NMS & NM \\
& PS & NS & NMS & NM & NMB & NB \\
& PB & NM & NMB & NB & NB & NB \\
\hline
\end{tabular}

TABLe 2: Fuzzy control output table.

\begin{tabular}{ccccccc}
\hline \multicolumn{5}{c}{$t_{o}(\mathrm{o})-t_{o}(\mathrm{o}-\mathrm{h})$} \\
& $(-\infty,-3 b)$ & $(-3 b,-b)$ & $(-b, b)$ & $(b, 3 b)$ & $(3 b$, \\
& & & & $+\infty)$ \\
\hline \multirow{4}{*}{$t_{0}(\mathrm{o})$} & $(-\infty,-3 a)$ & 45 & 45 & 45 & 43 & 41 \\
& $(-3 a,-a)$ & 41 & 39 & 37 & 35 & 33 \\
& $(-a, a)$ & 37 & 35 & 33 & 31 & 29 \\
& $(3 a, 3 a)$ & 33 & 31 & 29 & 27 & 25 \\
& $(3 a,+\infty)$ & 29 & 27 & 25 & 25 & 25 \\
\hline
\end{tabular}

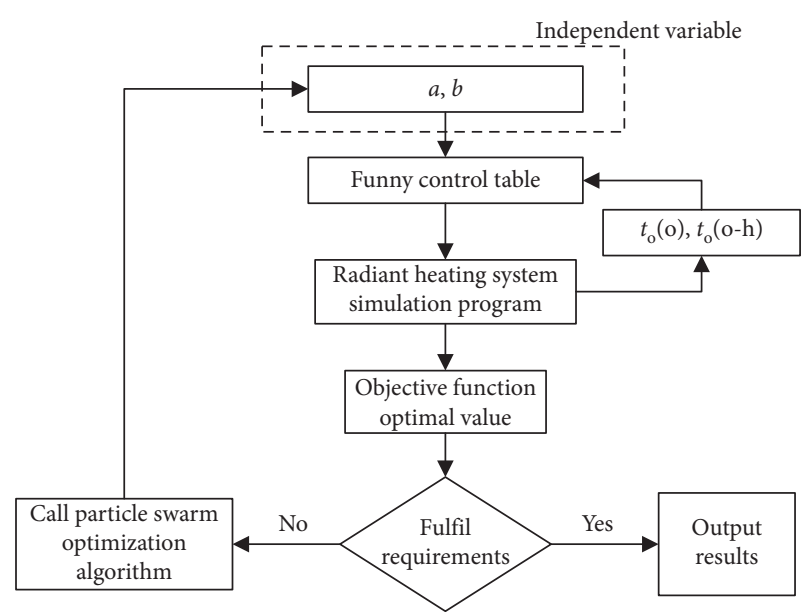

Figure 1: Fuzzy optimization calculation process.

where $H$ is total hours of heating season, $P_{\text {pump }, 45}$ is pump power under constant supplied water temperature of $45^{\circ} \mathrm{C}$, $P_{\text {awhp,45 }}$ is air-to-water heat pump power under constant supplied water temperature of $45^{\circ} \mathrm{C}, h_{\text {west }, 25}$ is room temperature of west bedroom below $18^{\circ} \mathrm{C}$ or above $19^{\circ} \mathrm{C}$ under constant supplied water temperature of $25^{\circ} \mathrm{C}, h_{\mathrm{liv}, 25}$ is room temperature of living room below $18^{\circ} \mathrm{C}$ or above $19^{\circ} \mathrm{C}$ under constant supplied water temperature of $25^{\circ} \mathrm{C}, h_{\text {bed,25 }}$ is room temperature of bedroom below $18^{\circ} \mathrm{C}$ or above $19^{\circ} \mathrm{C}$ under constant supplied water temperature of $25^{\circ} \mathrm{C}$, and $h_{\operatorname{din}, 25}$ is room temperature of dining room below $18^{\circ} \mathrm{C}$ or above $19^{\circ} \mathrm{C}$ under constant supplied water temperature of $25^{\circ} \mathrm{C}$.

\section{Engineering Example}

The building model uses a type 56 module from TRNSYS to simulate a single storey rural house with a building area of 


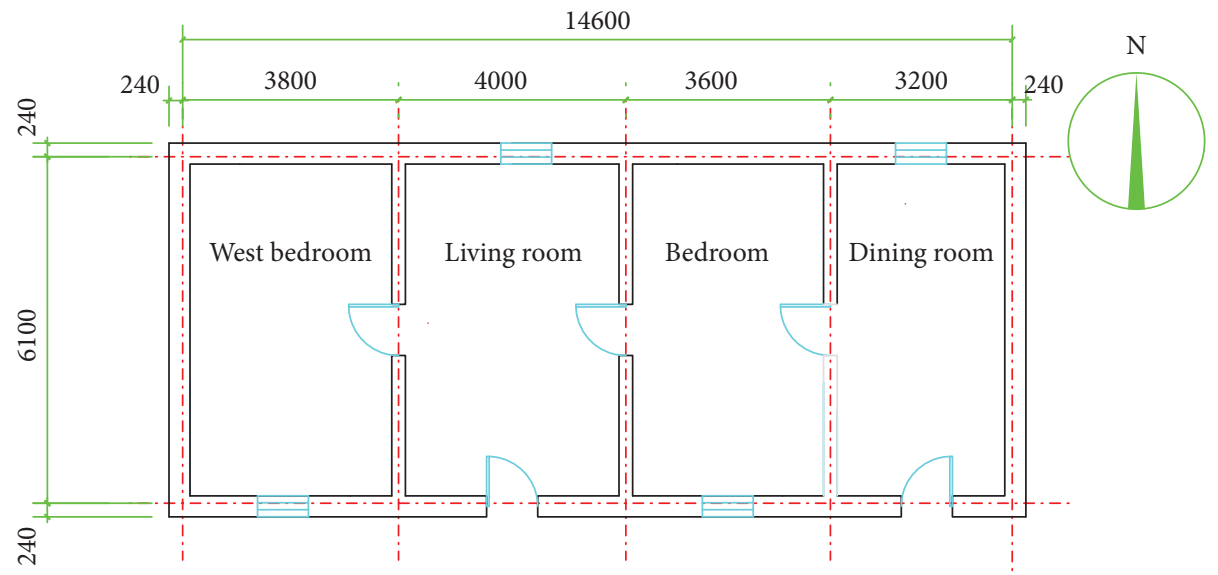

FIGURE 2: Architectural plane diagram of the typical rural residential building.

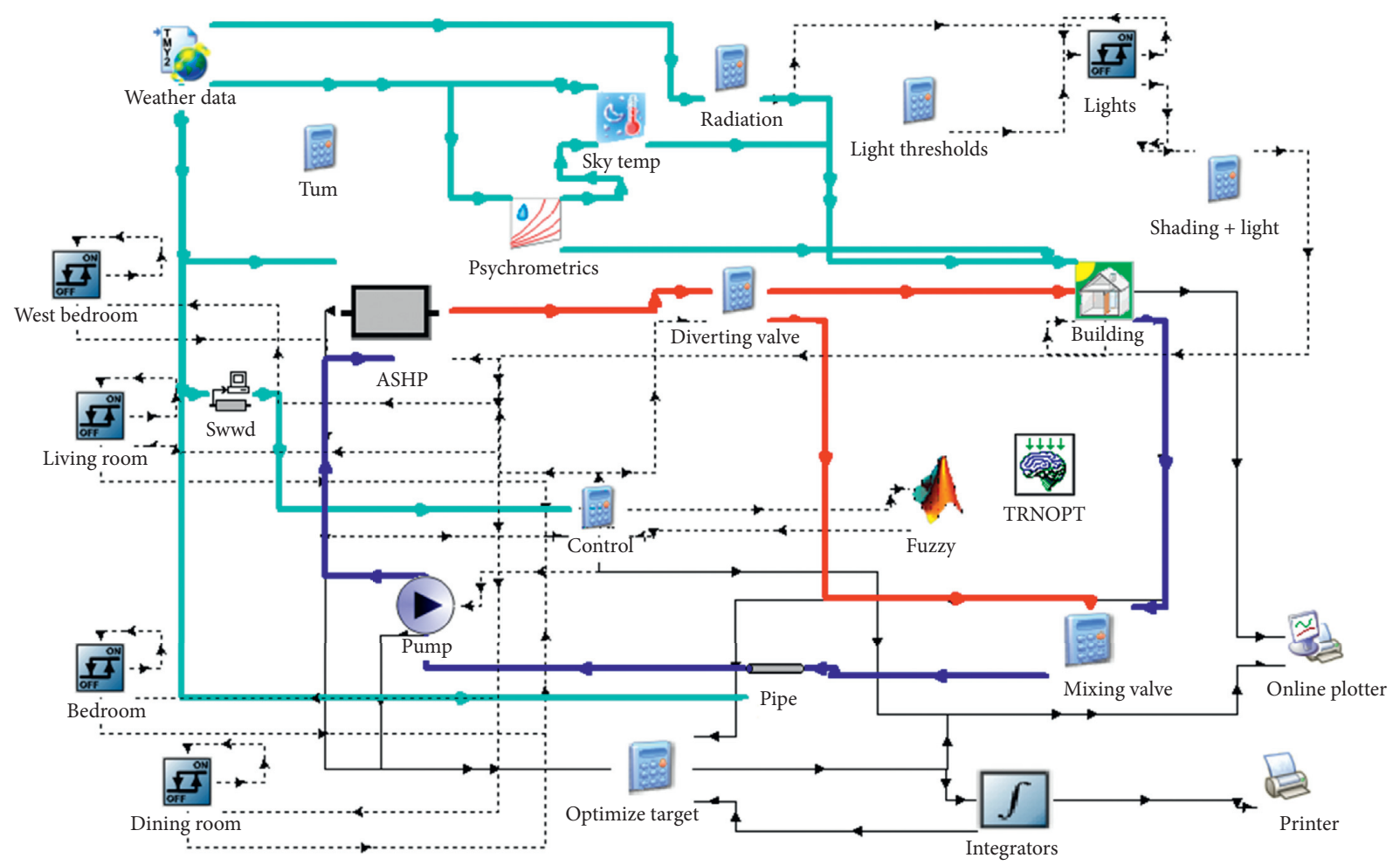

FIgURE 3: Floor radiant heating system with air-to-water heat pump.

$100 \mathrm{~m}^{2}$ (see Figure 2) and a height of $3.2 \mathrm{~m}$. The weather file in the model adopts the typical weather year TMY2 data file of Beijing.

The detailed setting of the building refers to the typical rural residential building in the cold area in reference [38]. The heating season starts on November 15 and lasts for 2,904 hours. The ratio of the south facing window to the wall is 0.1 , and the ratio of the north facing window to the wall is 0.05 . The number of ventilation is $1 / \mathrm{h}$. The basic information of the building is shown in Table 3.
The floor radiant heating surface is cement, the filling layer is $60 \mathrm{~mm}$ concrete, the bottom layer is provided with insulation layer, and the buried pipe adopts PE pipe. The rural residential building radiant coil parameters are shown in Table 4.

More information of the radiant coil is given in [39]. The simulation is carried out by considering the McQuay air-towater heat pump MACO50ER5-AE and the horizontal multistage centrifugal pump. Detail parameters are shown in Table 5 . 
TABLE 3: Architectural basic information.

\begin{tabular}{lc}
\hline Structure & Coefficient of heat transfer $\left(\mathrm{W} \mathrm{m}^{-2} \cdot \mathrm{K}^{-1}\right)$ \\
\hline Exterior wall & 0.457 \\
Roof & 0.422 \\
Ground & 0.039 \\
Exterior window & 2.8 \\
\hline
\end{tabular}

TABLE 4: Radiant coil parameters.

\begin{tabular}{lcc}
\hline & Unit & Parameter \\
\hline Pipe spacing & $\mathrm{m}$ & 0.2 \\
Pipe outer diameter & $\mathrm{m}$ & 0.02 \\
Pipe wall thickness & $\mathrm{m}$ & 0.002 \\
Pipe heat transfer coefficient & $\mathrm{W} \mathrm{m}^{-1} \mathrm{~K}^{-1}$ & 4.54 \\
\hline
\end{tabular}

TABLE 5: Equipment detail parameters.

\begin{tabular}{lccc}
\hline & Quantity & Rated heating capacity (kW) & Rated power (kW) \\
\hline Air-to-water heat pump & 1 & 14.8 & 4.4 \\
Pump & 1 & & 0.37 \\
\hline
\end{tabular}

The air-to-water heat pump floor radiant heating system is built by TRNSYS. The floor radiant heating system with air-to-water heat pump is shown in Figure 3.

\section{Results and Discussion}

The optimization result is shown in Table 6.

Beijing heating time is 2,904 hours in the whole heating season. Hourly ambient temperature is shown in Figure 4, and hourly ambient temperature change is shown in Figure 5.

As shown in Figures 4 and 5, the abscissa is the heating season time, and the ordinate in Figure 4 is the hourly ambient temperature. In Figure 5, the ordinate is the hourly ambient temperature change. The dotted lines in Figures 4 and 5 are the domain scopes optimized by PSO. The hourly ambient temperature of the entire heating season is $62.9 \%$ at $(-a, a)$. The hourly ambient temperature change of the entire heating season is $36.9 \%$ at $(-b, b)$. The temperature change of each room from January 6 to January 12 in the fuzzy control heat pump unit supplied water temperature is shown in Figure 6.

As shown in Figure 6, the abscissa is the heating season time, from January 6 to January 12, totaling $168 \mathrm{~h}$. The left ordinate is the room temperature of the west bedroom, living room, bedroom, and dining room and the supplied water temperature setting of the heat pump. The right ordinate is the outdoor ambient temperature. The temperature of each room in the whole heating season can be basically guaranteed at $18-19^{\circ} \mathrm{C}$. The room temperature of each room is fluctuated by the change of the outdoor ambient temperature and the supplied water temperature setting of the heat pump unit. The change in trend of the supplied water temperature of the heat pump unit and the outdoor ambient temperature is reversed.

As shown in Table 7, the SCOP of the whole heating season is 2.43 under constant control. This value is similar to
TABLE 6: Optimization value.

\begin{tabular}{ccccc}
\hline & Initial value & Range & Step value & Optimization value \\
\hline$a$ & 3 & {$[1,15]$} & 1 & 4.8 \\
$b$ & 1 & {$[0.1,6]$} & 0.1 & 0.5 \\
\hline
\end{tabular}

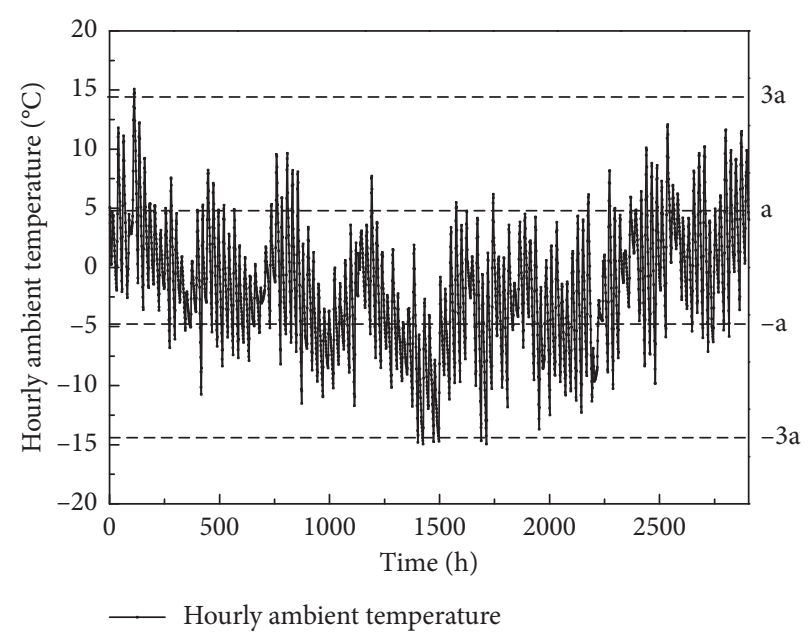

FIgURE 4: Hourly ambient temperature in the whole heating season.

the SCOP of existing air-to-water heat pump heating systems in rural areas of Beijing in the whole heating season [40]. The supplied water temperature under the fuzzy control can be saved energy by $15.9 \%$ compared with the constant supplied water temperature of $45^{\circ} \mathrm{C}$, and the heating system can increase the SCOP by $18.9 \%$. Comparing with the constant supplied water temperature of $45^{\circ} \mathrm{C}$, the room temperature is more stable which the unsatisfied time decrease $3.2 \%$ under the fuzzy control supplied water 


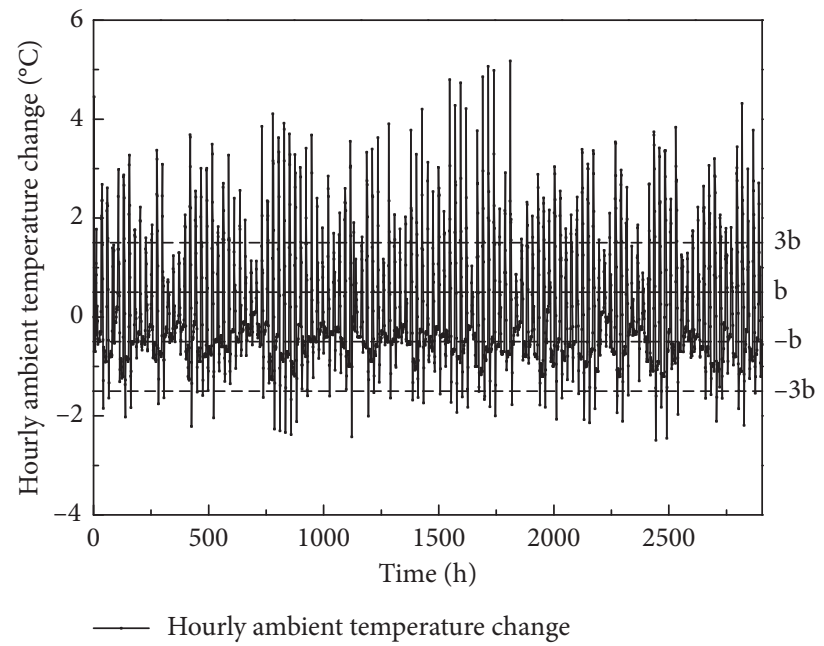

FIgURE 5: Hourly ambient temperature change in the whole heating season.

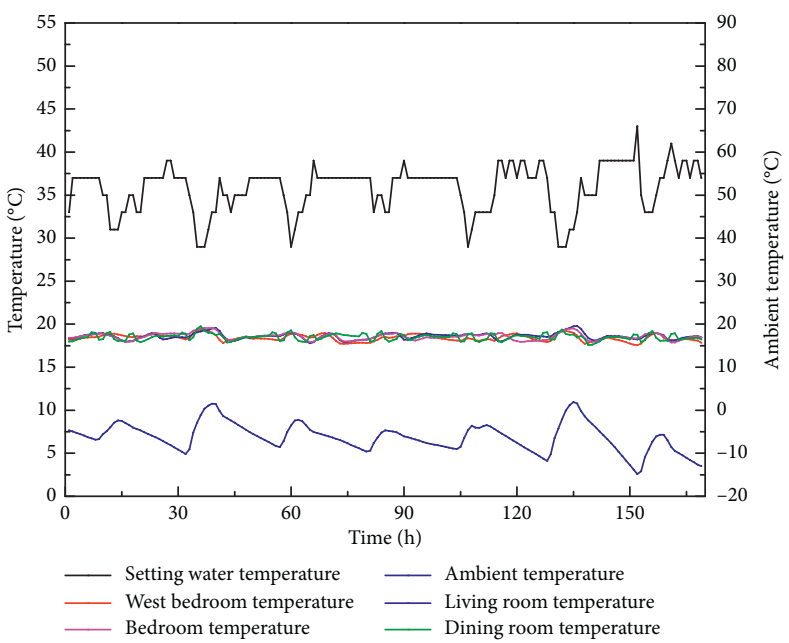

Figure 6: Room temperature under varied supplied water temperature fuzzy control.

TABLE 7: Heating system power consumption in the whole heating season.

\begin{tabular}{lcc}
\hline & Constant $45^{\circ} \mathrm{C}$ & Fuzzy control \\
\hline Power consumption $(\mathrm{kWh})$ & 5046 & 4242 \\
Unsatisfied time $(\mathrm{h})$ & 3085 & 2985 \\
SCOP & 2.43 & 2.89 \\
\hline
\end{tabular}

temperature. Under the premise of ensuring the room temperature, the unit supplied heat quantity does not change much, but the heat pump unit supplied water temperature and building load more matching, the average supplied water temperature of the unit is reduced. The efficiency of the heat pump unit is increased, and the power consumption of the heat pump unit is reduced.

Extend the control to other regions without changing the building envelope and air source heat pump heating capacity. Taking the climates of Zhengzhou, Qingdao, Beijing, Taiyuan, and Zhangjiakou as variables, monthly average ambient temperatures in the heating season are shown in Figure 7.
Optimization parameters of Zhengzhou, Qingdao, Beijing, Taiyuan, and Zhangjiakou are shown in Table 8.

As shown in Figure 8, room temperatures of Zhengzhou, Qingdao, Beijing, Taiyuan, and Zhangjiakou are stable under the fuzzy control of varied supplied water temperature. With the decrease of outdoor temperature in the heating season, the supplied water temperature setting of Zhangjiakou is significantly higher than that of Zhengzhou. Compare energy consumption and unsatisfied time of all rooms in each city as shown in Figure 9.

The more the room heat demand matches the heat supply, the less is the unsatisfied time. Comparing constant $45^{\circ} \mathrm{C}$ supplied water temperature, the unsatisfied time decrease by $0.5 \%, 0.2 \%, 3.2 \%, 2.8 \%$, and $3.8 \%$ in Zhengzhou, Qingdao, Beijing, Taiyuan, and Zhangjiakou under the fuzzy control supplied water temperature. The fuzzy control can not only improve the temperature stability of the room but also save energy. The fuzzy control is $18.0 \%, 17.2 \%, 15.9 \%$, $13.2 \%$, and $10.5 \%$ compared with constant $45^{\circ} \mathrm{C}$ in Zhengzhou, Qingdao, Beijing, Taiyuan, and Zhangjiakou, respectively, of energy conservation. The fuzzy control can 


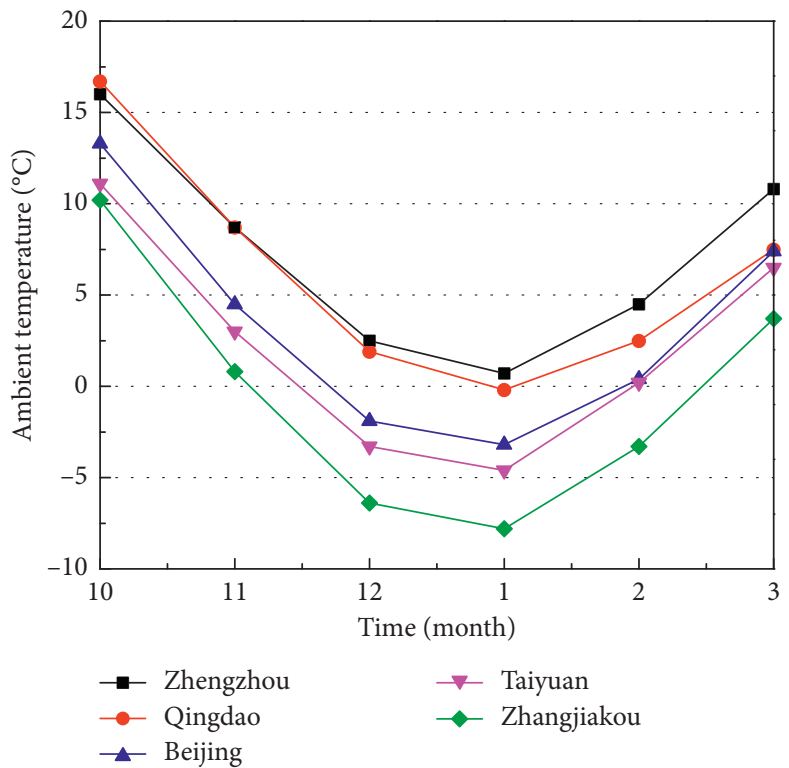

Figure 7: Monthly average ambient temperatures in the heating season.

TABLE 8: Optimization parameters of five cities.

\begin{tabular}{lccc}
\hline & Heating season (h) & $a$ & \\
\hline Zhengzhou & 2904 & 13.2 & 0.4 \\
Qingdao & 3384 & 7.4 & 0.3 \\
Beijing & 2904 & 4.8 & 0.5 \\
Taiyuan & 3624 & 4.8 & 0.2 \\
Zhangjiakou & 3624 & 4.0 & 0.1 \\
\hline
\end{tabular}

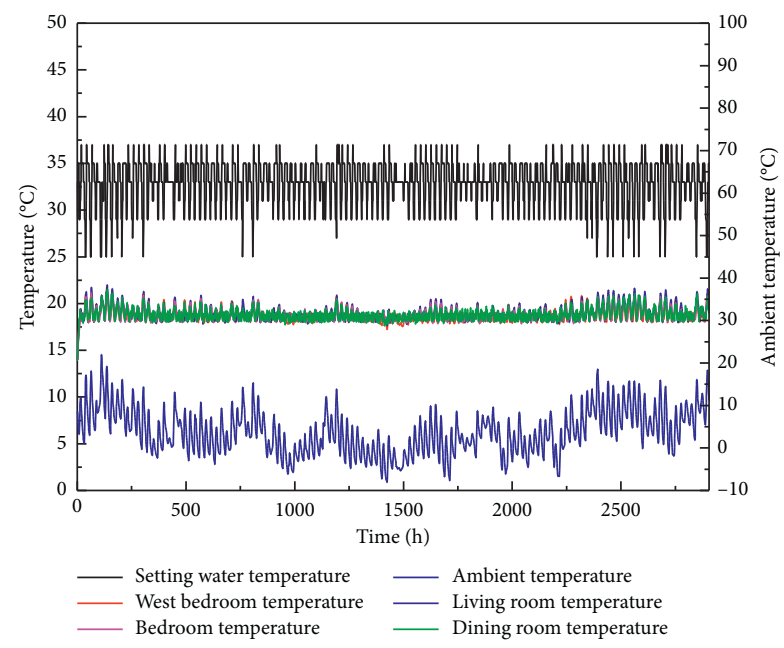

(a)

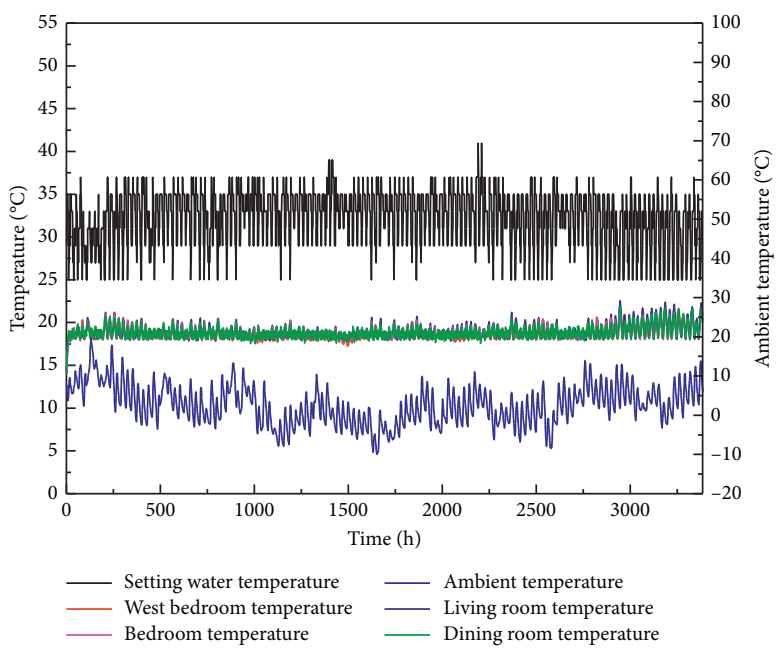

(b)

Figure 8: Continued. 


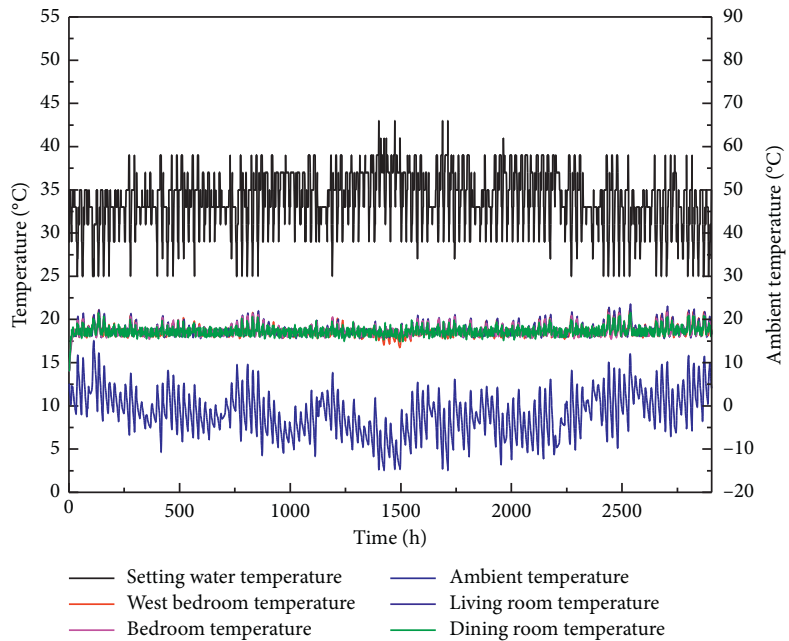

(c)

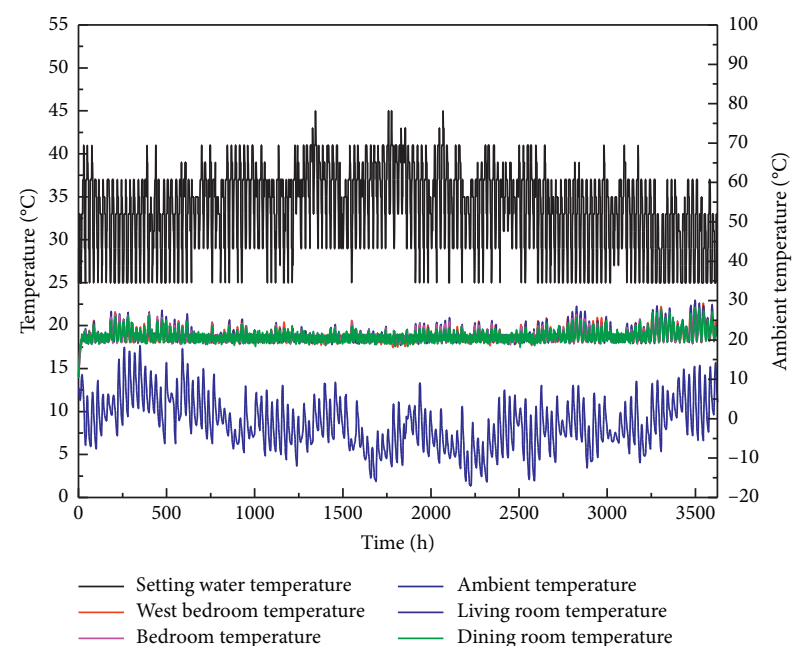

(d)

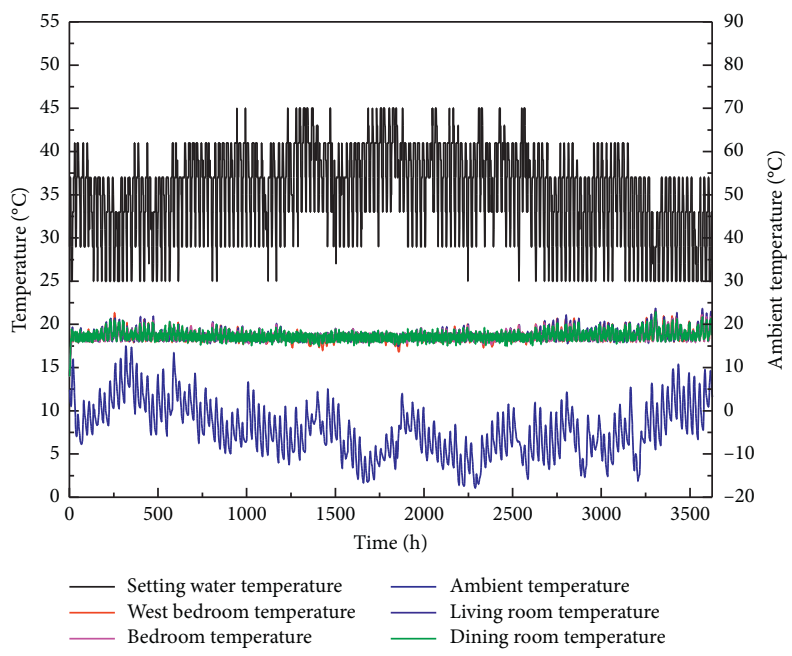

(e)

Figure 8: Room temperature curve under varied supplied water temperature fuzzy control: (a) Zhengzhou; (b) Qingdao; (c) Beijing; (d) Taiyuan; and (e) Zhangjiakou.

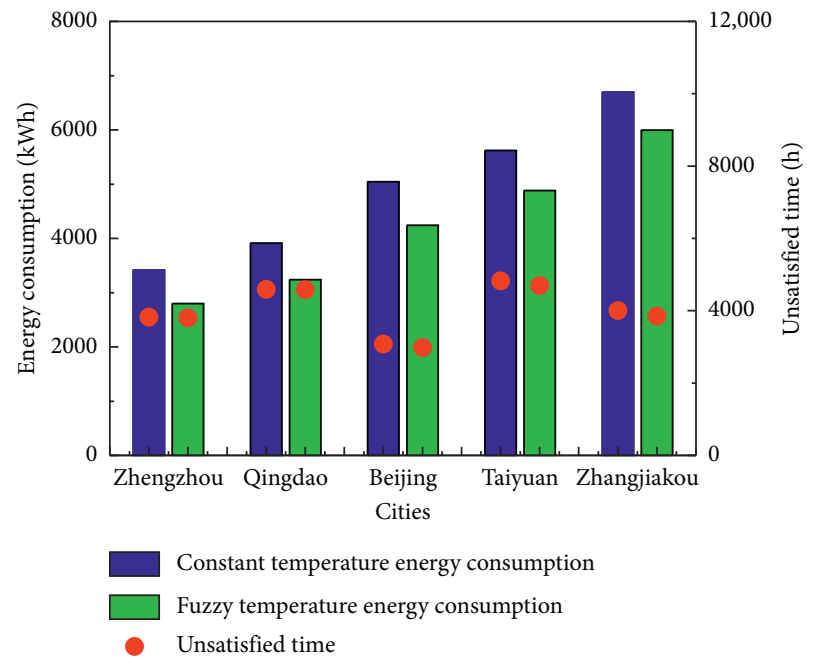

Figure 9: Energy consumption and unsatisfied time in the heating season. 
reduce $\mathrm{CO}_{2}$ emissions by $4.3 \mathrm{~kg} / \mathrm{m}^{2}, 4.7 \mathrm{~kg} / \mathrm{m}^{2}, 5.6 \mathrm{~kg} / \mathrm{m}^{2}$, $5.2 \mathrm{~kg} / \mathrm{m}^{2}$, and $4.9 \mathrm{~kg} / \mathrm{m}^{2}$ in Zhengzhou, Qingdao, Beijing, Taiyuan, and Zhangjiakou, respectively.

\section{Conclusions}

In this study, the calculation model of air-to-water heat pump floor radiant heating system with the typical building of $100 \mathrm{~m}^{2}$ in cold regions in the north is built on the TRNSYS software platform. The fuzzy rules are formulated by MATLAB software. The fuzzy control for adjusting the supplied water temperature by the difference between the current ambient temperature and the previous hour's ambient temperature and the ambient temperature during the heating season. The particle swarm optimization algorithm of GenOpt software platform optimizes the domain in the fuzzy control table to obtain the best fuzzy control table. The study results show that compared with the control of constant supplied water temperature of $45^{\circ} \mathrm{C}$, the fuzzy control variable supplied water temperature can save energy $15.9 \%$ in the heating season, and improve SCOP $18.9 \%$ in the heating season, and room temperature stability has also been improved. The fuzzy control is extended to Zhengzhou, Qingdao, Taiyuan, and Zhangjiakou, which can save $18.0 \%$, $17.2 \%, 13.2 \%$, and $10.5 \%$ energy consumption, respectively. While ensuring the temperature of the room, the fuzzy control can reduce $\mathrm{CO}_{2}$ emissions by $4.3 \mathrm{~kg} / \mathrm{m}^{2}, 4.7 \mathrm{~kg} / \mathrm{m}^{2}$, $5.6 \mathrm{~kg} / \mathrm{m}^{2}, 5.2 \mathrm{~kg} / \mathrm{m}^{2}$, and $4.9 \mathrm{~kg} / \mathrm{m}^{2}$ in Zhengzhou, Qingdao, Beijing, Taiyuan, and Zhangjiakou, respectively.

\section{Abbreviations}

ABC: Artificial bee colony

ANN: Artificial neural network

BEM: Building energy model

EA: Evolutionary algorithm

FL: $\quad$ Fuzzy logic

GA: Genetic algorithm

PMV: Predicted mean vote

PPD: Predicted percentage dissatisfied

PSO: Particle swarm optimization

SVM: Support vector machine

SCOP: System coefficient of performance

\section{Data Availability}

The data used to support the findings of this study are available from the corresponding author upon request.

\section{Conflicts of Interest}

The authors declare that there are no conflicts of interest regarding the publication of this paper.

\section{Acknowledgments}

The authors would like to thank the funding support from the GOC/WB/GEF, under the program "Incentive Policy Research and Tool Development for High Percentage of RE
Combined for Heating in the Northern Area of China" (Project no. A3CS2016007).

\section{References}

[1] Z. Zhuang, Y. Li, B. Chen, and J. Guo, "Chinese kang as a domestic heating system in rural Northern China-a review," Energy and Buildings, vol. 41, no. 1, pp. 111-119, 2009.

[2] M.-S. Yeo, I.-H. Yang, and K.-W. Kim, "Historical changes and recent energy saving potential of residential heating in Korea," Energy and Buildings, vol. 35, no. 7, pp. 715-727, 2003.

[3] S. B. Leiqh and C. R. Mac Cluer, "Comparative study of proportional flux-modulation and various types of temperature-modulation approaches for radiant floor-heating system control," Ashrae Transactions, vol. 100, pp. 1040-1053, 1994.

[4] B. W. Olesen, K. Sommer, and B. Düchting, "Control of slab heating and cooling systems studied by dynamic computer simulations," Ashrae Transactions, vol. 108, pp. 698-707, 2002.

[5] A. Afram and F. Janabi-Sharifi, "Theory and applications of HVAC control systems-a review of model predictive control (MPC)," Building and Environment, vol. 72, pp. 343-355, 2014.

[6] K. Henrik and H. Carl-Eric, "Application of model based predictive control for water-based floor heating in low energy residential buildings," Building and Environment, vol. 46, pp. 556-569, 2011.

[7] D. Liu, L. Z. Wang, R. Z. Wang, and X. Q. Zhai, "Application analysis of floor radiant heating system," Chinese Journal of Refrigeration Technology, vol. 36, pp. 50-55, 2016.

[8] D. B. Crawley, L. K. Lawrie, F. C. Winkelmann et al., "EnergyPlus: creating a new-generation building energy simulation program," Energy and Buildings, vol. 33, no. 4, pp. 319-331, 2001.

[9] A. Trnsys, Transient System Simulation Program, University of Wisconsin, Madison, WI, USA, 2000.

[10] J. Moon, K. Kim, and H. Min, "ANN-based prediction and optimization of cooling system in hotel rooms," Energies, vol. 8, no. 10, pp. 10775-10795, 2015.

[11] A. Afram, F. Janabi-Sharifi, A. S. Fung, and K. Raahemifar, "Artificial neural network (ANN) based model predictive control (MPC) and optimization of HVAC systems: a state of the art review and case study of a residential HVAC system," Energy and Buildings, vol. 141, pp. 96-113, 2017.

[12] K. Feng, J. Lu, and J. Chen, "Nonlinear model predictive control based on support vector machine and genetic algorithm," Chinese Journal of Chemical Engineering, vol. 23, no. 12, pp. 2048-2052, 2015.

[13] M. Killian and M. Kozek, "Implementation of cooperative Fuzzy model predictive control for an energy-efficient office building," Energy and Buildings, vol. 158, pp. 1404-1416, 2018.

[14] M. Fiorentini, J. Wall, Z. Ma, J. H. Braslavsky, and P. Cooper, "Hybrid model predictive control of a residential HVAC system with on-site thermal energy generation and storage," Applied Energy, vol. 187, pp. 465-479, 2017.

[15] H. Huang, L. Chen, and E. Hu, "A new model predictive control scheme for energy and cost savings in commercial buildings: an airport terminal building case study," Building and Environment, vol. 89, pp. 203-216, 2015.

[16] E. Carrascal, I. Garrido, A. Garrido, and J. Sala, "Optimization of the heating system use in aged public buildings via model predictive control," Energies, vol. 9, no. 4, p. 251, 2016. 
[17] R. R. Germán, L. S. Eva, and F. B. Carlos, "Model predictive control optimization via genetic algorithm using a detailed building energy model," Energies, vol. 12, p. 34, 2019.

[18] G. Ciulla, V. Lo Brano, and A. D’Amico, "Modelling relationship among energy demand, climate and office building features: a cluster analysis at European level," Applied Energy, vol. 183, pp. 1021-1034, 2016.

[19] A. Martínez-Ibernón, C. Aparicio-Fernández, R. Royo-Pastor, and J.-L. Vivancos, "Temperature and humidity transient simulation and validation in a measured house without a HVAC system," Energy and Buildings, vol. 131, pp. 54-62, 2016.

[20] A. Cacabelos, P. Eguía, J. L. Míguez, E. Granada, and M. E. Arce, "Calibrated simulation of a public library HVAC system with a ground-source heat pump and a radiant floor using TRNSYS and GenOpt," Energy and Buildings, vol. 108, pp. 114-126, 2015.

[21] R. Z. Homod, K. S. M. Sahari, H. A. F. Almurib, and F. H. Nagi, "Gradient auto-tuned takagi-sugeno fuzzy forward control of a HVAC system using predicted mean vote index," Energy and Buildings, vol. 49, pp. 254-267, 2012.

[22] C. Verhelst, D. Degrauwe, F. Logist, J. Van Impe, and L. Helsen, "Multi-objective optimal control of an air-to-water heat pump for residential heating," Building Simulation, vol. 5, no. 3, pp. 281-291, 2012.

[23] S. Prívara, J. Siroký, L. Ferkl, and J. Cigler, "Model predictive control of a building heating system: the first experience," Energy and Buildings, vol. 43, no. 2-3, pp. 564-572, 2011.

[24] A. Lefort, R. Bourdais, G. Ansanay-Alex, and H. Guéguen, "Hierarchical control method applied to energy management of a residential house," Energy and Buildings, vol. 64, pp. 53-61, 2013.

[25] M. Wetter, "GenOpt: generic optimization program," http:// gundog.lbl.gov/GO/.

[26] L. Chen, S. Du, Y. He, M. Liang, and D. Xu, "Robust model predictive control for greenhouse temperature based on particle swarm optimization," Information Processing in Agriculture, vol. 5, no. 3, pp. 329-338, 2018.

[27] E. Khanmirza, A. Esmaeilzadeh, and A. H. D. Markazi, "Design and experimental evaluation of model predictive control vs. intelligent methods for domestic heating systems," Energy and Buildings, vol. 150, pp. 52-70, 2017.

[28] G. Domenico and V. Antonio, "Genetic algorithms based reference signal determination for temperature control of residential buildings," Applied Science, vol. 8, p. 2129, 2018.

[29] L. D. S. Coelho and V. C. Mariani, "Improved firefly algorithm approach applied to chiller loading for energy conservation," Energy and Buildings, vol. 59, pp. 273-278, 2013.

[30] M. Hu, J. D. Weir, and T. Wu, "Decentralized operation strategies for an integrated building energy system using a memetic algorithm," European Journal of Operational Research, vol. 217, no. 1, pp. 185-197, 2012.

[31] K. F. Fong, V. I. Hanby, and T. T. Chow, "A robust evolutionary algorithm for HVAC engineering optimization," HVAC\&R Research, vol. 14, no. 5, pp. 683-705, 2008.

[32] N. Delgarm, B. Sajadi, and S. Delgarm, "Multi-objective optimization of building energy performance and indoor thermal comfort: a new method using artificial bee colony (ABC)," Energy and Buildings, vol. 131, pp. 42-53, 2016.

[33] J. Kennedy and R. Eberhart, "Particle swarm optimization," in Proceedings of the IEEE International Conference on Neural Networks, pp. 1942-1948, Perth, Western Australia, November 1995.
[34] T. Weber and G. Jóhannesson, "An optimized RC-network for thermally activated building components," Building and Environment, vol. 40, no. 1, pp. 1-14, 2005.

[35] Y.-H. Li and W.-C. Kao, "Taguchi optimization of solar thermal and heat pump combisystems under five distinct climatic conditions," Applied Thermal Engineering, vol. 133, pp. 283-297, 2018.

[36] C. Verhelst, F. Logist, J. Van Impe, and L. Helsen, "Study of the optimal control problem formulation for modulating airto-water heat pumps connected to a residential floor heating system," Energy and Buildings, vol. 45, pp. 43-53, 2012.

[37] L. Cabrol and P. Rowley, "Towards low carbon homes-a simulation analysis of building-integrated air-source heat pump systems," Energy and Buildings, vol. 48, pp. 127-136, 2012.

[38] J. Li, Y. Zou, and J. Liu, "Study on building envelope optimization parameters and energy-saving rate of rural residential buildings in severe cold and cold zones," Building Science, vol. 28, pp. 6-9, 2012.

[39] D. H. Jiang, H. S. Cui, K. D. Jiang, and J. L. Yang, "Study building heat storage operation strategy for air-to-water heat pumps connected to a residential floor heating system," The Third International Conference on Energy Engineering and Environmental Protection, vol. 227, p. 4, 2019.

[40] H. M. Zhou, N. P. Gao, Z. Li, A. S. Li, H. Y. Zhao, and Y. F. Gao, "Measured analysis of air source heat pump heating system in Beijing rural area," Gas Heat, vol. 38, pp. 32-39, 2018. 